http://dx.doi.org/10.30681/23588403v13i0212

\title{
POKEMON GO: GAMIFICAÇÃO, APRENDIZAGEM TANGENCIAL E ENSINO DE LÍNGUA
}

Data de recebimento: 17/07/2018

Aceite: 25/11/2018

Geraldo José Rodrigues LISKA (UNIFAL-MG) ${ }^{1}$

Resumo: A mania Pokémon GO chamou a atenção pública em realidade aumentada. Como sempre ocorre com os usos recém populares de tecnologia, a comunidade educativa logo começou a explorar como usar o jogo no ensino e aprendizagem, incluindo na segunda aprendizagem de línguas. Nenhuma aprendizagem profunda ocorre se os aprendizes não fizerem um compromisso de longo prazo com ela. Dada a sua natureza e status sociocultural, os jogos móveis possuem um grande potencial para melhorar a motivação, o interesse, a interação e o engajamento. Neste artigo, apresentamos o game Pokemon GO como exemplo do uso de jogos móveis em uma variedade de ambientes de aprendizagem. Exemplos mais concretos sobre uma variedade de conceitos e dentro de uma variedade de configurações e assuntos são necessários, a fim de construir um entendimento mais abrangente sobre o uso de jogos móveis em ambientes de aprendizagem formal e informal. O artigo foi construído utilizando-se dos princípios de aprendizagem de Gee (2003, 2004, 2005, 2008, 2014), da aprendizagem tangencial e da utilização do jogo para o ensino de língua.

Palavras-Chave: gamificação; aprendizagem tangencial; ensino de língua.

Abstract: Pokémon GO craze attracted public attention in augmented reality. As always with the newly popular uses of technology, the educational community soon began to explore how to use the game in teaching and learning, including second language learning. No deep learning occurs if learners do not make a long-term commitment to it. Given their nature and sociocultural status, mobile games have great potential for improving motivation, interest, interaction and engagement. In this article, we present the Pokemon GO game as an example of the use of mobile games in a variety of learning environments. More concrete examples on a variety of concepts and within a variety of settings and subjects are needed in order to build a more comprehensive understanding of the use of mobile gaming in formal and informal learning environments. The article was constructed using Gee's learning principles (2003, 2004, 2005, 2008, 2014), tangential learning and game use for language teaching.

Keywords: gamification; tangential learning; language teaching.

\section{Introdução}

Pokémon GO é um dos aplicativos mais baixados para Android e IOS. Em menos de um mês desde o seu lançamento, conquistou o posto de o mais jogado nos Estados Unidos,

\footnotetext{
${ }^{1}$ Doutor em Estudos Linguísticos (UFMG). Secretário Executivo da UNIFAL-MG. geliska@ gmail.com
} 
superando o desempenho de outros jogos há mais tempo consagrados no mercado mobile. E não somente jogos, o Pokémon GO também superou grandes aplicativos como Twitter, Tinder e até mesmo o Instagram.

De acordo com informações do aplicativo na Play Store, Pokemon GO foi baixado mais de 650 milhões de vezes e foi nomeado como o melhor jogo móvel por The Game Developers Choice Awards ${ }^{2}$ e também como o melhor aplicativo do ano por TechCrunch ${ }^{3}$, um website focado em notícias sobre tecnologia, bem como perfis de empresas, produtos e sites.

O aplicativo é grátis para jogar e oferece compras dentro do jogo. É otimizado para smartphones, mas não para tablets.

O principal objetivo do jogo é sair pela cidade capturando criaturas Pokémon. Para capturar criaturas nos Pokéstops e batalhar nos Ginásios, o jogador deve estar no local indicado no mapa (Figuras 1 e 2).

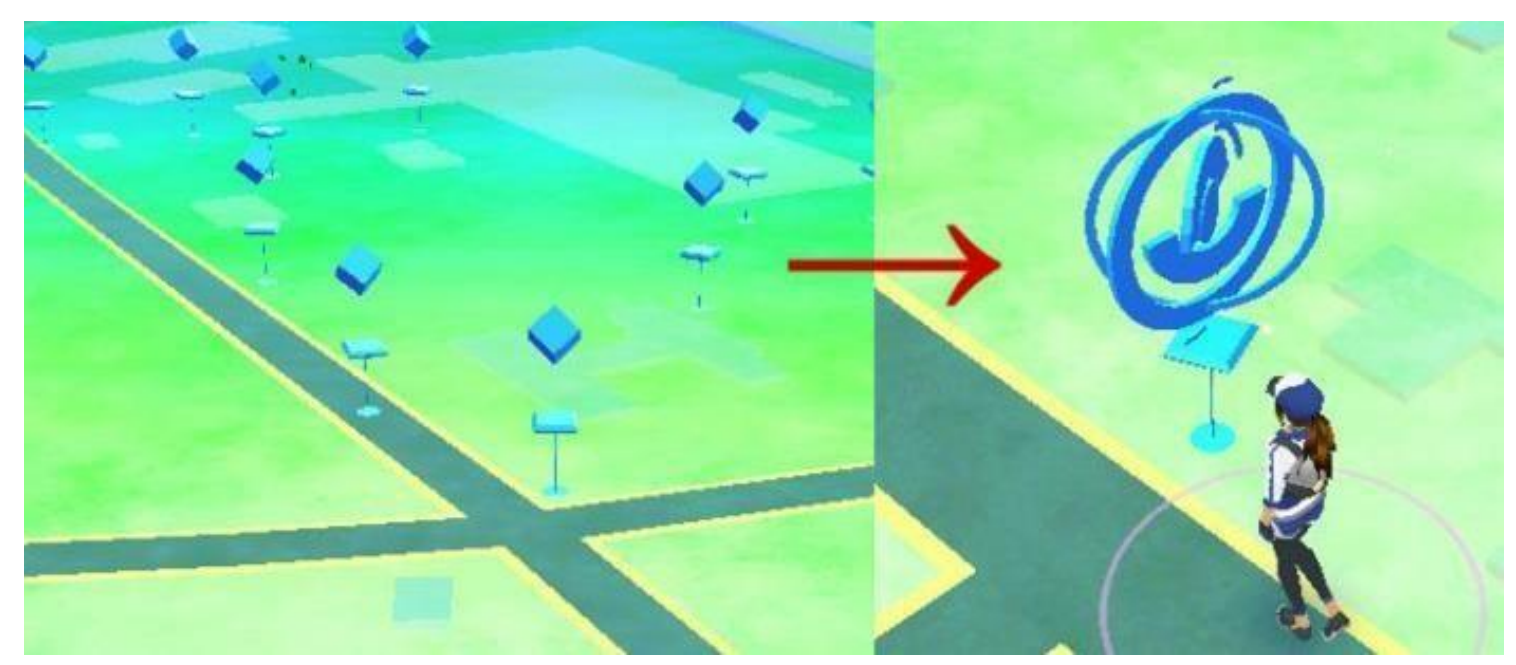

Figura 1: Pokestops (lugares marcados no mapa, geralmente construções e lugares históricos onde o jogador pode encontrar itens do jogo como: PokéBolas, ovos de Pokémon, ovos e outros itens que ajudam na evolução do Pokémon)
Fonte: do autor

2 Prêmio criado pela International Game Developers Association para os desenvolvedores de jogos e entretenimento entregue desde 2001. Disponível em http://www.gamechoiceawards.com/, acesso em 18 out. 2017. ${ }^{3}$ Disponível em https://techcrunch.com/, acesso em 18 out. 2017. 


\section{Revista de Estudos Acadêmicos de Letras}

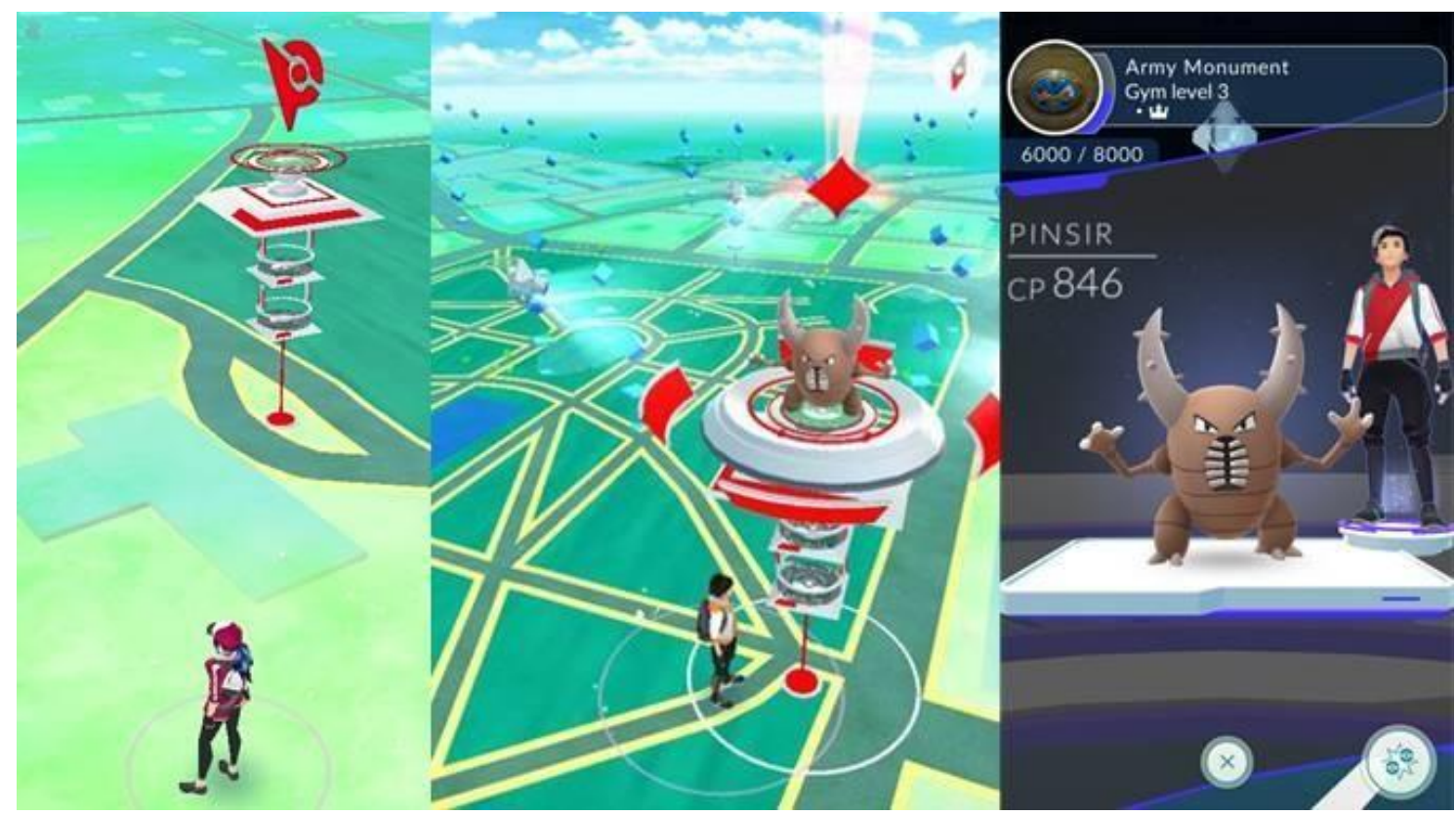

Figura 2: Ginásio (para entender a imagem, o $1^{\circ}$ quadro mostra o ginásio quando o jogador está próximo a ele, mas não o suficiente para batalhar, o $2^{\circ}$ quadro mostra o ginásio pronto para a batalha, com a figura de um Pokemon do líder desse ginásio no topo, e o $3^{\circ}$ quadro mostra informações do líder e suas criaturas, após selecionar o ginásio).

Fonte: Do autor

Nas cidades maiores há diversos pontos que atraem os jogadores até eles, construindo um fator social, e gerando uma comunidade cada vez mais imersa no jogo. Vários desses lugares já são atrações turísticas, uma vez que é utilizada uma base de dados com pontos georreferenciados.

Conforme Carli, Gastal e Gomes (2016), além de estratégias próprias a cada jogo, a sua criação e a sua organização dependem, basicamente, de duas tecnologias: georreferenciamento e realidade aumentada. O georreferenciamento do smartphone serve para definir a localização do jogador. A realidade aumentada é utilizada para simular e projetar as criaturas no mundo real, por meio da captura das imagens da câmera.

Concordamos com Santos et al (2016) que Pokemon GO surge como o game que se opõe à imagem de um jogador sedentário trancado em uma sala e vidrado em uma tela. Como recurso de ensino, ele vem ao encontro da necessidade de abertura da escola para a cidade e de levar o aluno a experimentar o conhecimento local, mas conectado ao global. Na perspectiva da interdisciplinariedade, da identidade, da transversalidade do ensino e da aprendizagem tangencial (como veremos nas próximas seções), as possibilidades se multiplicam: integração do conhecimento da história, da arte, da cultura e da 


\section{Revista de Estudos Acadêmicos de Letras}

sociedade no espaço, já que o jogo não foi pensado como escola e suas divisões artificiais, mas sim como realidade aumentada e integrada, como a vida real.

Além disso, revela-se de grande importância para o ensino da geografia: conhecimento, reflexão e construção do espaço geográfico, compreensão dos sistemas de localizações com base nas coordenadas geográficas e, de maneira geral, compreensão e aplicabilidade da cartografia.

\section{PRINCÍPIOS DE APRENDIZAGEM DE (GEE, 2003, 2004, 2005) EM POKEMON GO}

Borges (2013), apoiado nas ideias de Gee (2004), defende que as necessidades de aprendizagem que o jogo requer para que o jogador vença os desafios é que contribui para proporcionar entretenimento e, consequentemente, a repetibilidade, o desejo de o jogador permanecer continuamente jogando no ambiente.

O jogo digital ainda não tem sido explorado pelos profissionais da educação com todo o seu potencial para aprendizagem, como faz a indústria do entretenimento, tanto que os jogos comerciais com ênfase em entretenimento são, notoriamente, mais aceitos (e comprados) pelas crianças do que aqueles que possuem fins educativos formais.

Gee (2004) alerta que os desenvolvedores de jogos educativos têm muito que aprender com os desenvolvedores de jogos da indústria do entretenimento. Uma observação que se faz sobre os jogos educacionais é que eles, muitas vezes, são vistos pelas crianças como tarefas. Isso porque eles exigem da criança um conhecimento prévio sobre a aprendizagem do conteúdo formal da escola que é trabalhado no jogo como instruções explícitas. Embora contribuam para a aprendizagem e sejam considerados mais agradáveis do que as tarefas tradicionais, falta aos jogos educacionais a repetibilidade que os jogos de entretenimento possuem.

No entanto, acredita-se que o jogo pode divertir e proporcionar aprendizagem de conteúdos que são pertinentes para a formação escolar, despertando o interesse da criança em jogá-lo, independentemente da vontade de professores e pais. Se os jogos educacionais forem utilizados, fora do espaço escolar, com um alto grau de repetibilidade, poderia até se pensar em serem incorporados pela indústria do entretenimento como um diferencial e um atrativo para as vendas. Para isso é preciso conhecer mais sobre como requerer aprendizagens que tornem os desafios instigantes e atrativos para que o jogador se divirta. 


\subsection{Identidade}

Nenhuma aprendizagem profunda ocorre se os aprendizes não fizerem um compromisso de longo prazo com ela. Aprender alguma coisa em um novo campo, seja física ou carpintaria, requer que o aprendiz assuma uma nova identidade: assuma o compromisso de ver e de valorizar o trabalho e o mundo da forma como o fazem os bons físicos e carpinteiros.

Desde o início do jogo, o jogador é convidado a customizar seu personagem com o que mais lhe for atraente (Figura 3). As opções de customização incluem cor de cabelo, pele e olhos, além de diversos formatos de chapéus, óculos, partes de cima (camisetas, jaquetas), partes de baixo (calças, bermudas), mochilas, luvas, meias e calçados. Alguns itens só podem ser adquiridos com uso de Pokecoins, a moeda do jogo. Para ganhá-las, o jogador deve participar de batalhas em ginásios ou, uma forma mais fácil, utilizar o cartão de crédito por meio do Google Play. Para ter ideia, com R\$3,19 é possível adquirir 100 Pokecoins.
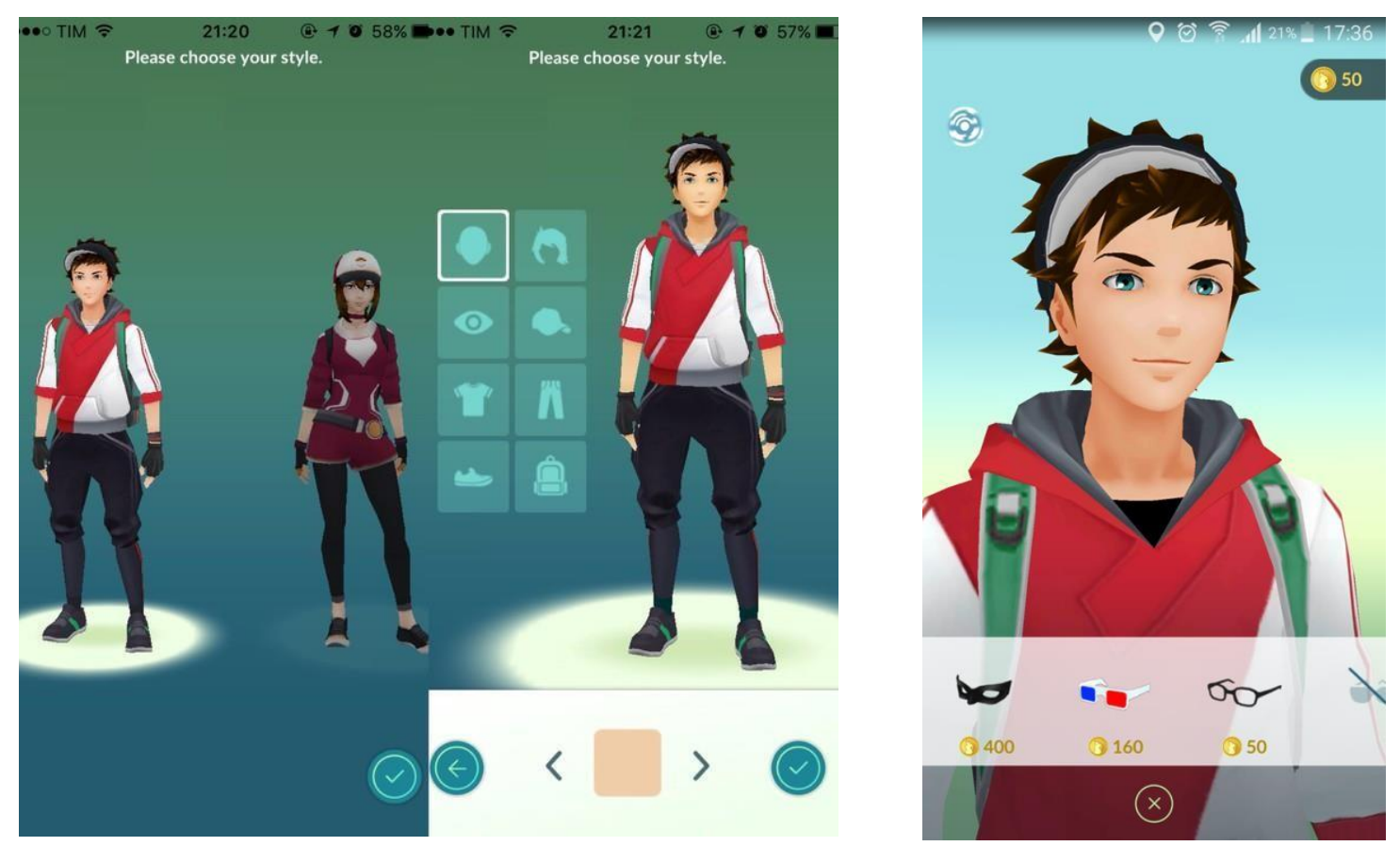

Figura 3: Customização do personagem (o jogador pode escolher, inicialmente, um personagem do gênero masculino ou feminino e escolher entre várias opções de customização, algumas gastando Pokecoins, como modelos de óculos).

Fonte: Do autor.

Como o jogo trabalha com sistema de geolocalização, o ambiente de captura é o mesmo em que o jogador se encontra, o que possibilita maior identificação com game. 


\section{Revista de Estudos Acadêmicos de Letras}

\subsection{Desafio e consolidação}

Bons jogos oferecem aos jogadores um conjunto de problemas desafiadores e então os deixam resolver esses problemas até que tenham virtualmente rotinizado ou automatizado suas soluções. Depois que isso acontece, o jogo lança uma nova classe de problemas aos jogadores, exigindo que eles repensem sua recém adquirida maestria, que aprendam algo novo e que integrem este novo aprendizado ao seu conhecimento anterior. Essa nova maestria, por sua vez, é consolidada pela repetição (com variações) para ser novamente desafiada. Este ciclo foi chamado “Ciclo da Expertise" (BEREITER; SCARDAMALIA, 1993); é o modo como cada um se torna expert em qualquer coisa em que valha a pena ser expert.

Em Pokemon GO, à medida que o jogador avança no jogo, surgem novos desafios. Por exemplo, para poder batalhar em ginásios, o personagem deve estar no level 5 (Figura 4). A única forma de chegar a esse nível é capturando os monstros que aparecem.

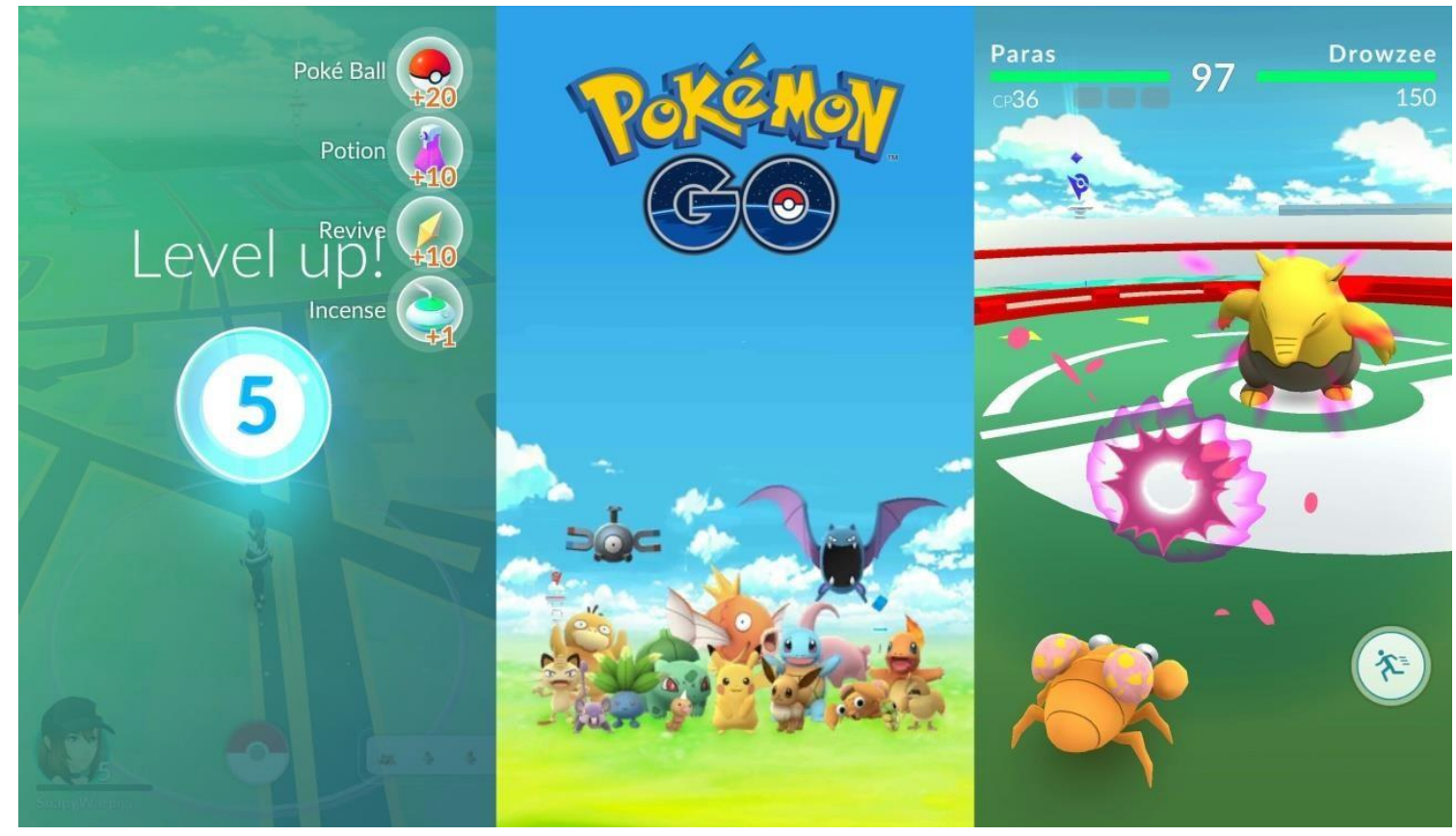

Figura 4: Para poder batalhar em ginásios, o personagem deve estar no level 5

Fonte: Do autor

Depois de pegar um monte de Pokémon, o personagem atingirá o Nível 5. Neste nível poderá acessar os Gyms - mas, antes de fazer isso, deve se alinhar com uma equipe. Estar em uma equipe permite se juntar a outros jogadores locais.

Cada equipe está ligada a um pássaro lendário: Team Instinct tem Zapdos, Team Mystic tem Articuno, e Team Valor tem Moltres (Figura 5). No momento, não há nada que mostre que estar em uma equipe irá fornecer quaisquer benefícios além da capacidade de reforçar companheiros de equipe em Gyms e treinar Pokémon. 
Ginásios executados por colegas de equipe dão lugar para ganhar experiência e aumentar o prestígio dos ginásios.

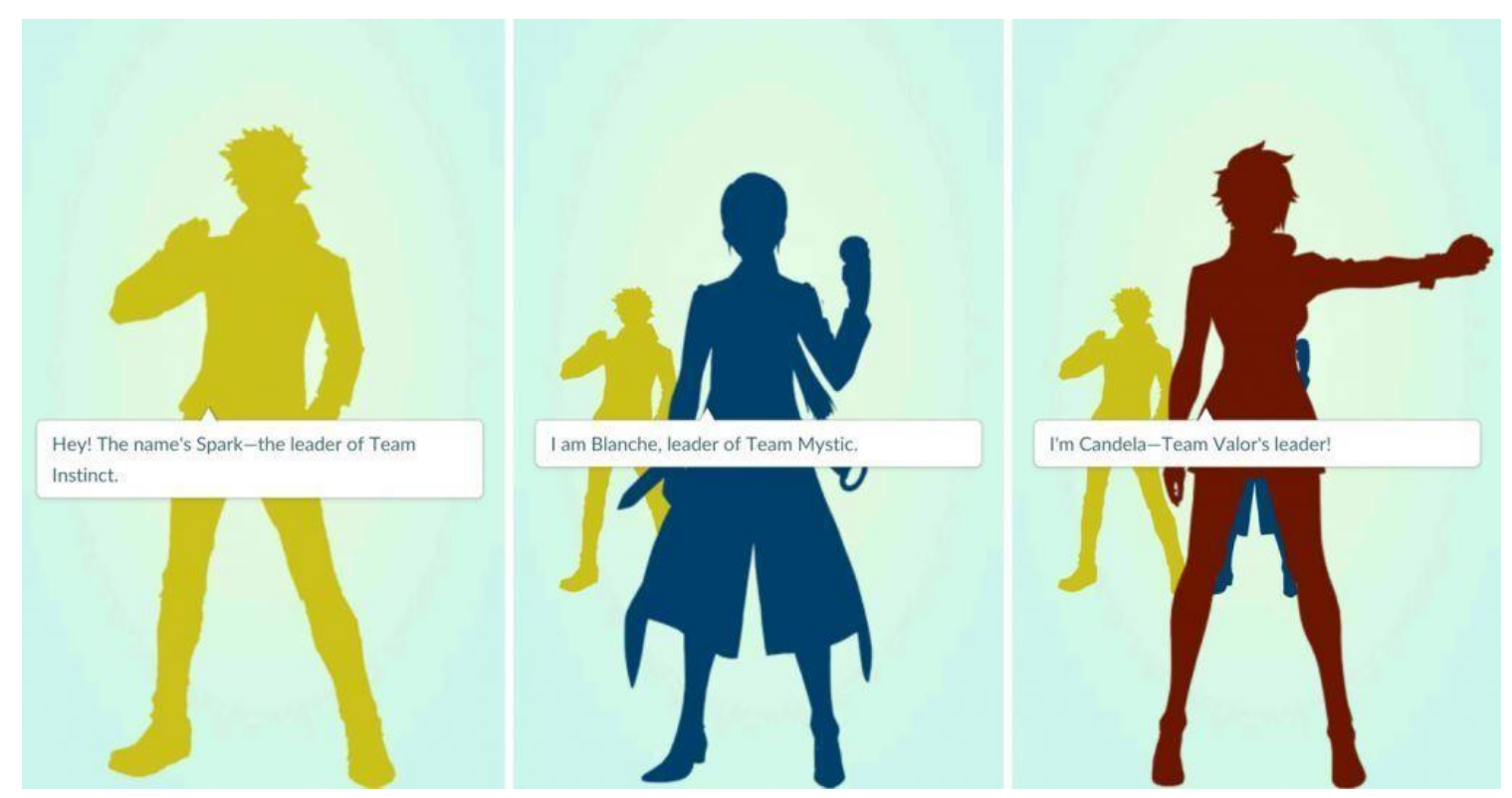

Figura 5: Momento em que o jogador deve escolher a qual time se filiar. Fonte: Do autor

\subsection{Frustração prazerosa}

Os bons games ficam dentro do "regime de competência" (DISESSA, 2000, apud GEE, 2005) do jogador, mas junto ao limite externo desse regime. Ou seja, eles são percebidos como "factíveis", mas desafiadores. É um estado altamente motivador para os aprendizes.

Em Pokemon GO, a captura dos monstros que aparecem exige complexidade à medida que os atributos dessas criaturas aumentam. Além disso, o nível de dificuldade varia de acordo com a raridade do Pokemon: Quanto mais raro, mais difícil de pegar (Figura 6). 


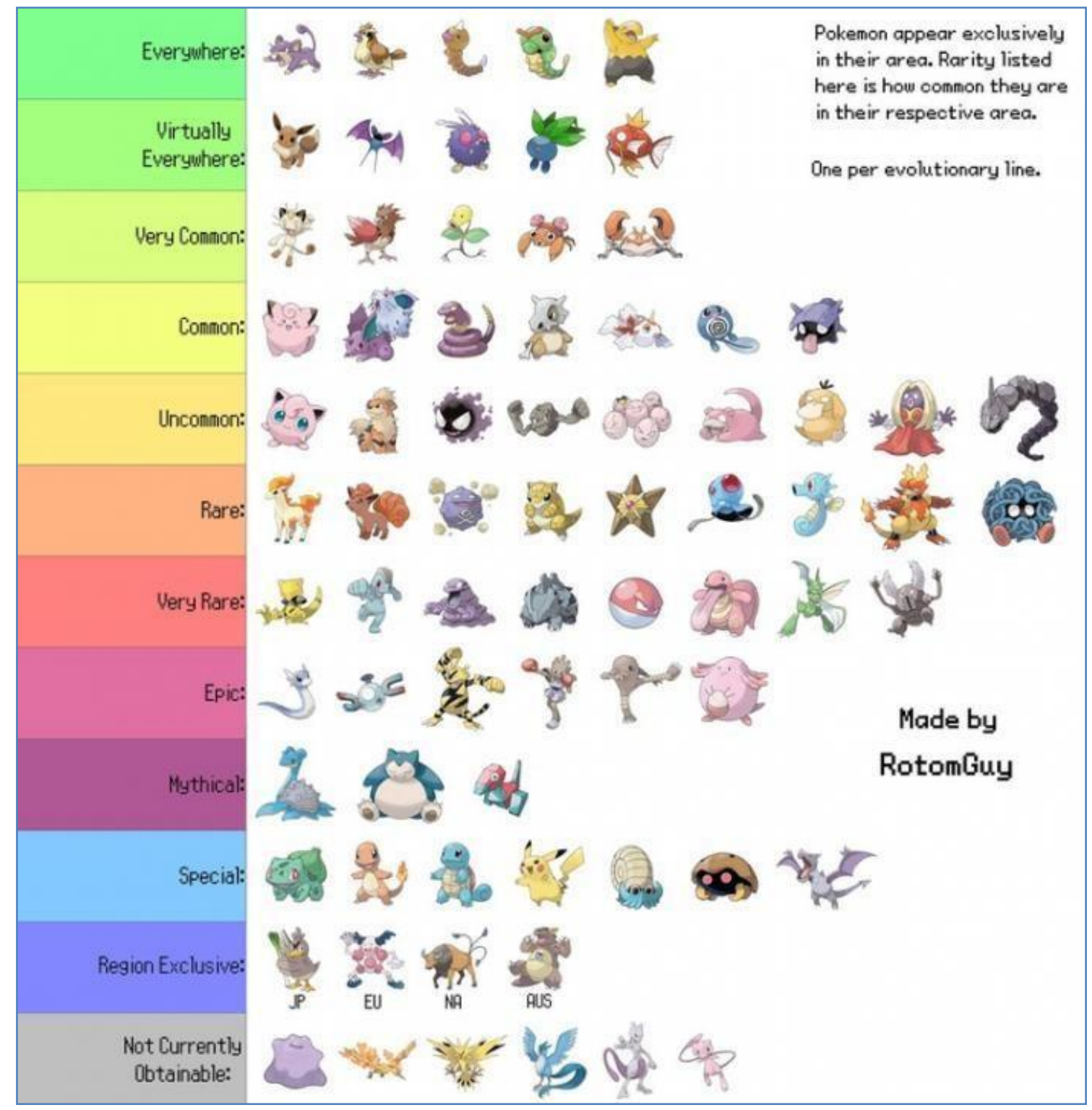

Figura 6: Nível de raridade dos Pokemon

Disponível em https://static2.i4u.com/sites/default/files/images/content_images/1_150.jpg

Para isso, as pokebolas (Figura 7) são distribuídas em tipos com níveis de rendimento. Aquelas de níveis mais elevados são proporcionalmente mais complicadas de se obter nas Pokestops, a menos que o jogador queira comprá-las por meio do cartão de crédito. Aquele jogador que não quer gastar dinheiro com o jogo, provavelmente terá maior frustração para conseguir alcançar os objetivos, no entanto a experiência possivelmente será mais prazerosa. 


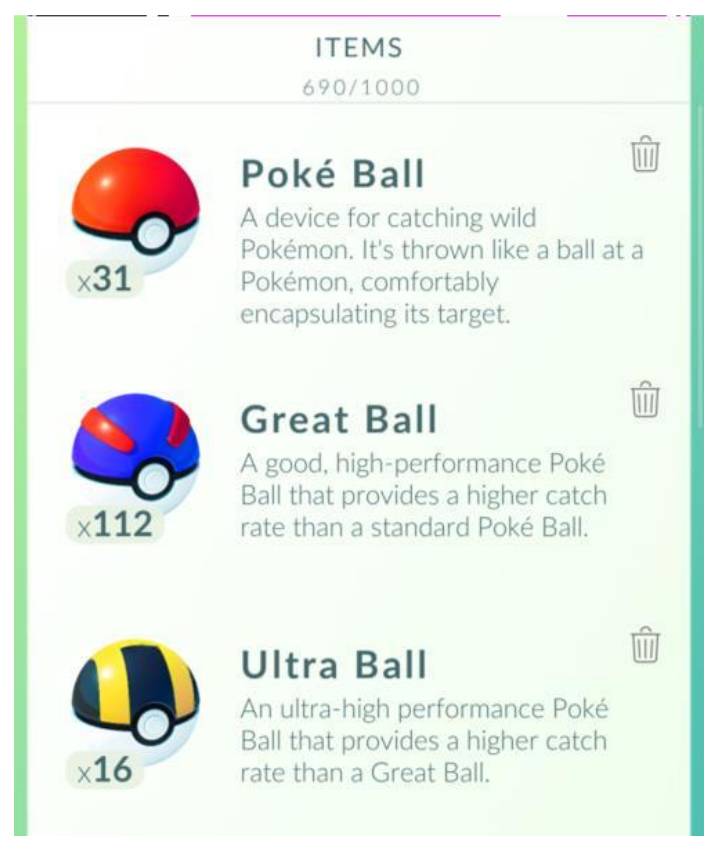

Figura 7: Tipos de Pokebolas

Fonte: Do autor

\section{POKEMON GO E APRENDIZAGEM TANGENCIAL}

A aprendizagem tangencial ocorre quando o aluno tem contato com o conhecimento sem perceber a intenção de ensiná-lo. Mesmo que a aprendizagem não ocorra dentro do jogo, criamse cenários e desperta-se o interesse do estudante para a pesquisa sobre determinado assunto. Em alguns casos, os estudantes consideram que as aulas não são atraentes, por isso não se envolvem com elas e, consequentemente, não aprendem direito.

Nesse sentido, a aprendizagem tangencial é importante para o processo de ensino e aprendizagem. $\mathrm{O}$ objeto de estudo não precisa ser necessariamente o tema principal do jogo digital. A estratégia do aprendizado tangencial também é um conceito promissor para promover mais aprendizado autodirigido e proativo. Consequentemente, os jogos digitais podem ser ferramentas importantes no processo de aprendizagem, motivadores e geradores de curiosidade.

Os aplicativos móveis que combinam o jogo com a atividade física levam a uma atividade substancial a curto prazo e, ao contrário de muitas intervenções existentes e aplicativos de saúde móvel, têm potencial para alcançar populações pobres em atividades (ALTHOFF; WHITE; HORVITZ, 2016).

Seguindo essa tendência de inovação e de convergência tecnológica, o Pokemon GO surge como o game que se opõe a imagem de um jogador sedentário trancado em uma sala e 


\section{Revista de Estudos Acadêmicos de Letras}

vidrado em uma tela. Como recurso de ensino, ele vem ao encontro da necessidade de abertura da escola para a cidade e de levar o aluno a experimentar o conhecimento local, mas conectado ao global.

As possibilidades de aplicação no ensino de geografia, por exemplo, são muitas: conhecimento, reflexão e construção do espaço geográfico, compreensão dos sistemas de localizações com base nas coordenadas geográficas e, de maneira geral, compreensão e aplicabilidade da cartografia.

Na perspectiva da interdisciplinariedade ou transversalidade do ensino, as possibilidades se multiplicam: integração do conhecimento da história, da arte, da cultura e da sociedade no espaço, já que o jogo não foi pensado como escola e suas divisões artificiais, mas sim como realidade aumentada e integrada, como a vida real.

\section{POKEMOM GO, ENSINO E APRENDIZAGEM DE LÍNGUA}

As escolas atuais enfrentam grandes problemas em torno da motivação e do envolvimento dos alunos. Gamificação, ou a incorporação de elementos de jogo em configurações não jogo, oferece uma oportunidade para ajudar as escolas a resolver esses problemas difíceis. Se a gamificação é útil para as escolas, devemos então entender melhor o que é gamificação, como funciona e por que pode ser útil.

Defendemos, assim como Lee e Hammer (2011), que o potencial da gamificação vai além de promover estilos de vida saudáveis e estratégias de marketing. Os jogadores voluntariamente investem inúmeras horas no desenvolvimento de suas habilidades de resolução de problemas no contexto dos jogos (GEE, 2008). Eles reconhecem o valor da prática estendida e desenvolvem qualidades pessoais, como persistência, criatividade e resiliência através do jogo prolongado. A gamificação tenta aproveitar o poder motivacional dos jogos e aplicá-lo aos problemas do mundo real.

Educadores de língua descobriram aspectos diferentes de jogar Pokémon GO passíveis de aprendizagem de línguas, como foi o caso do Ingress ${ }^{4}$, que tem sido utilizado principalmente para aprender Inglês. Como dissemos, o primeiro passo para se jogar é criar um avatar pessoal.

${ }^{4}$ Disponível em https://games2teach.uoregon.edu/2015/11/02/ingress-for-language-learning/ , acesso em 14 out. 2017. 


\section{Revista de Estudos Acadêmicos de Letras}

Esse processo envolve vocabulário relacionado à aparência física: escolher cor, sexo, roupa, olhos e cabelo, etc (GODWIN-JONES, 2016).

Além disso, há a possibilidade de criar arquivos de imagem ao jogar Pokémon GO para serem usadas em narrativas digitais. Os jogadores, por exemplo, podem ativar a câmera do dispositivo móvel ao encontrar um Pokémon, então tirar um screenshot, colocando o monstro no contexto da cena ao vivo. Uma série dessas imagens pode ser colocada em uma narrativa. Esse processo pode ser auxiliado por ferramentas disponíveis no Pokémon GO, incluindo a revista (journal), que registra todas as ações do jogo e da Pokédex, que fornece informações sobre cada Pokémon. Parte da narrativa poderia envolver cartografia, com base na coleta de coordenadas GPS.

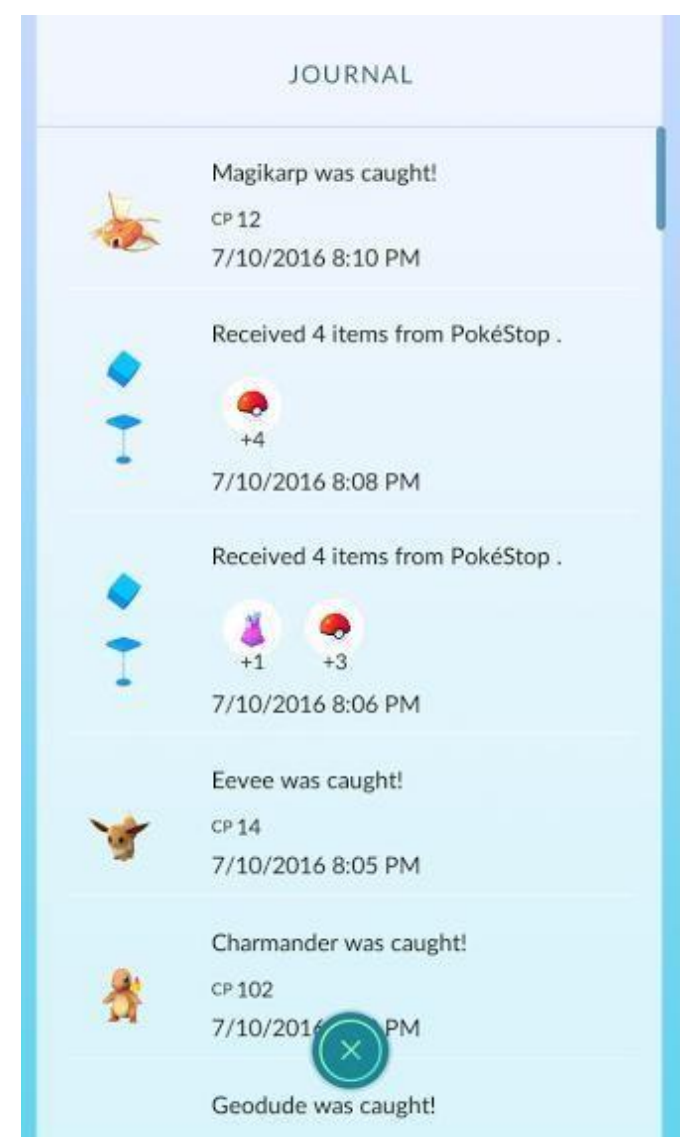

Figura 8: Exemplo de jornal

Fonte: Do autor

Os jogadores podem também criar narrativas ou produções midiáticas em torno da área de um PokéStop. Isso pode envolver a criação de uma imagem panorâmica usando um aplicativo como o Google Street View ou Ricoh Theta S (GODWIN-JONES, 2016). 


\section{Revista de Estudos Acadêmicos de Letras}

De acordo com Godwin-Jones (2016), Pokémon GO não foi projetado para a aprendizagem de línguas e muitas das maneiras que os professores alistaram poderiam ser aplicadas a outros jogos móveis comerciais. A vantagem de essas atividades serem realizadas com Pokémon GO é a popularidade do jogo. Isso permite uma possível integração da aprendizagem com uma atividade divertida em que os alunos são envolvidos por sua própria escolha. O grande número de jogadores também significa que é fácil encontrar colegas jogadores. Na verdade, nas PokéStops é possível juntar-se com outros jogadores. Isso também é provável em um ginásio, um local onde Pokémon de um jogador pode fazer a batalha.

Como em todos os jogos digitais, também existem fóruns e sites de companhia que foram criados em apoio à jogabilidade e como ponto de encontro para os jogadores. Coletamos na internet uma página que fez traduções dos principais termos do Pokémon GO em português, o que pode ser utilizado no ensino (Quadro 1):

Quadro 1 - Tradução dos principais termos do Pokémon GO em português

Tips - Dicas

Pokédex - Lista de todos os pokémons disponíveis no jogo

Shop - Loja

Pokéballs - Pokébolas

Incense - Incenso

Lucky Egg - Ovo da Sorte

Lure Module - Módulo de Isca

Egg Incubator - Incubadora de Ovos

Bag Upgrade - Melhoramento da Mochila (aumento de espaço para segurar itens)

Pokémon Storage Upgrade - Melhoramento de Armazenamento de Pokémons (aumento de espaço para guardar Pokémons)

Potion - Poção (Um remédio em spray para tratar ferimentos. Restaura o HP de um Pokémon em 20 pontos)

Super Potion - Super Poção (Um remédio em spray para tratar ferimentos. Restaura o HP de um Pokémon em 50 pontos)

Revive - Reanimar (Um remédio que consegue reanimar um Pokémon desmaiado. Também restaura metade do HP máximo de um Pokémon desmaiado)

Great Ball - Ótima Bola (Uma Pokébola boa e de alta performance que dá uma taxa de captura maior do que a de uma Pokébola normal) 
Razz Berry - Baga Razz, "Amora" (Dê isto a um Pokémon e será mais fácil capturá-lo)

Camera - Câmera (Quando encontrar um Pokémon em estado selvagem, pode usar sua câmera para tirar uma fotografia dele)

Settings - Definições

Music - Música

Sound Effects - Efeitos Sonoros

Vibration - Vibração

Battery Saver - Economizador de Bateria

Send Pokémon GO-related events, promotions, offers and news updates to my email address

- Enviar eventos, promoções, ofertas e notícias de atualizações relacionados com Pokémon GO para o meu endereço de e-mail.

Quick Start - Início Rápido

Help Center - Centro de Ajuda

Report High-Priority Issue - Reportar Problema de Alta Prioridade

About Pokémon GO - Sobre Pokémon GO

Sign Out - Sair

Fonte: Disponível em https://www.aficionados.com.br/pokemon-go-portugues/, acesso em 10 out. 2017.

\section{CONSIDERAÇÕES FINAIS}

Nosso objetivo neste trabalho foi contribuir para a consolidação do uso de jogos móveis como ferramentas de aprendizagem no contexto de uma variedade de ambientes formais e informais de aprendizagem. Essas tecnologias avançadas oferecem vantagens sobre as tecnologias da geração anterior, tanto em termos de gráficos, como reconhecimento de voz, velocidade e telas sensíveis ao toque.

A mania Pokémon GO chamou a atenção pública em realidade aumentada. Como sempre ocorre com os usos recém populares de tecnologia, a comunidade educativa logo começou a explorar como usar o jogo no ensino e aprendizagem, incluindo a segunda aprendizagem de línguas.

As interações sociais que acompanham o jogo de Pokémon GO ou outros jogos online podem proporcionar um espaço fértil para o uso da linguagem e aprendizagens. Como o jogo se expandiu geograficamente, tem sido testado por uma comunidade online global, multilíngue e multicultural que oferece grandes oportunidades para a interação social. 


\section{REFERÊNCIAS BIBLIOGRÁFICAS}

ALTHOFF, T.; WHITE, R. W.; HORVITZ, E. Influence of Pokemon GO on physical activity: Study and implications. J Med Internet Res, 18(12):e315, Dec 2016.

BEREITER, C. SCARDAMALIA, M. Surpassing Ourselves: An Inquiry Into the Nature and Implications of Expertise. Chicago: Open Court, 1993.

BORGES, A. P. Jogo digital para reconhecimento de palavras: análise comparativa entre as versões com instruções implícitas e explícitas. 2013. 163 f. Tese (Doutorado em Estudos Linguísticos) - Faculdade de Letras, Universidade Federal de Minas Gerais, Belo Horizonte.

CARLI, I. C. S. ; GASTAL, S. A.; GOMES M. C.. Pokémon Go, Realidade Aumentada e Georeferenciamento: A gamificação nas suas possibilidades para o Turismo.. Hospitalidade Revista da Universidade Anhembi, v. 13, p. 1-17, 2016.

GEE, J. P. What video games have to teach us about learning and literacy. New York: Palgrave/Macmillan, 2003.

. Situated language and learning: a critique of traditional schooling. London: Routledge, 2004.

. Why video games are good for your soul: pleasure and learning. Melbourne: Common Ground, 2005.

. Learning and games. In Katie Salen (Ed.) The ecology of games: Connecting youth, games, and learning (John D. and Catherine T. MacArthur Foundation series on digital media and learning). Cambridge, MA: The MIT Press, 2008.

. Principles of Game-based Learning, Video Games and Learning, Coursera, 2014. 
GODWIN-JONES, R. (2016). Augmented reality and language learning: From annotated vocabulary to place-based mobile games. Language Learning \& Technology, 20(3), 9-19, 2016.

LEE, J. J.; HAMMER, J. Gamification in education: what, how, Why Bother? Definitions and uses Exchange Organizational Behavior Teaching Journal, 15 (2), 2011, pp. 1-5

SANTOS, E. R.; FELIPE, G.; ROCHA, L. A.; CORREIA JR, P. de A. Pokémon Go: a maior experiência mundial reunindo cartografia digital e realidade aumentada. Anais 2016 (Ano II) da Semana de Ensino, Pesquisa e Extensão (SEPE). Instituto Federal Catarinense Campus Araquari, 2016. 